\title{
COSTA RICA Y PANAMÁ EN LA INDEPENDENCIA LOS CONTACTOS ENTRE LAS AUTORIDADES DE COSTA RICA Y PANAMÁ EN LA ÉPOCA DE LA SEPARACIÓN DE ESPAÑA
}

\author{
COSTA RICA AND PANAMA IN THE INDEPENDENCE \\ CONTACTS BETWEEN THE AUTHORITIES OF COSTA \\ RICA AND PANAMA DURING THE INDEPENDENCE \\ FROM SPAIN
}

\section{Jorge Francisco Sáenz Carbonell ${ }^{1}$

\section{RESUMEN}

El artículo explica los antecedentes inmediatos de la independencia de Costa Rica y Panamá de España y cómo ambas se independizaron por separado de España, en 1821, y se refiere a los contactos que mantuvieron en 1822 y 1823 . En el texto se hace referencia a las frecuentes relaciones comerciales que desde inicios del dominio español mantenían los habitantes de Costa Rica y Panamá, y se analiza cómo ambas circunscripciones se vieron brevemente afectadas a causa de la nueva distribución política-administrativa emanada de la Constitución de Cádiz. Con la independencia de España, abrazada por Costa Rica en octubre y por Panamá en noviembre de 1821 , podría haberse llegado a que convergieran en un mismo destino político-administrativo. Sin embargo, con la misma emancipación aparecieron nuevas potencias hegemónicas cuya presencia determinó el diverso destino de una y otra. Eso no impidió que se mantuvieran los vínculos comerciales ni que las autoridades superiores de Costa Rica y Panamá tuvieran en 1822 y 1823 contactos de gran cordialidad.

Palabras clave: Centralismo; comercio; constitución; federalismo; independencia; Junta Gubernativa

\begin{abstract}
The article explains the immediate background of the independence of Costa Rica and Panama from Spain and how they both became independent separately in 1821 and refers to the contacts they maintained in 1822 and 1823 . The close trade relationships among the inhabitants of Costa Rica and Panama are mentioned and the effects of the Constitution of Cádiz regarding the new political-administrative division are analyzed. After the independence from Spain, in the case of Costa Rica in October and for Panama in November of 1821, emerged a possibility for both of them to build a new country. Nevertheless, after their independence new hegemonic powers appeared and their presence defined a very different fates for each territory. Despite all this, the trade exchange prevailed and the contact between the highest authorities of Costa Rica and Panama in 1822 and 1823 was friendly.
\end{abstract}

Keywords: Centralism; constitution; federalism; Governing Board; independence; trade

1 Universidad de Costa Rica (UCR). Catedrático. Doctor en Educación con énfasis en Mediación Pedagógica. Correo electrónico: vladimirpaley@yahoo.com 


\section{Introducción}

Costarricenses y panameños celebran en 2021 el bicentenario de su independencia de España, que fue casi simultánea, porque Costa Rica la declaró en octubre de 1821 y Panamá al mes siguiente. Empero, las circunstancias que llevaron a tales decisiones fueron muy diferentes, como también el rumbo que siguió uno y otro territorio.

Durante el dominio español, para Costa Rica había sido vital su relación comercial con Panamá, que era el principal mercado para sus exportaciones agropecuarias; por su parte, Panamá, cuya principal fuente de recursos era el intenso tráfico de personas y mercaderías por su territorio y en sus puertos, carecía de una producción agrícola y ganadera suficiente como para satisfacer las demandas del comercio ístmico y, en consecuencia, apreciaba los productos costarricenses, aunque ciertamente no eran los únicos que se le ofrecían. La vecindad geográfica hizo que desde el siglo XVI esas relaciones comerciales entre Costa Rica y Panamá fueran constantes y a veces muy intensas (Fonseca, 2001; Molina, 1991 y Solórzano, 1984).

Aunque en algunas oportunidades pasajeras el territorio costarricense estuvo bajo la jurisdicción de la Real Audiencia de Panamá, en 1568 quedó adscrito, de manera definitiva a la de Guatemala. Dada la enorme distancia entre Guatemala y Costa Rica, la dificultad y lentitud de los transportes y otros factores, la pertenencia de la provincia al reino de Guatemala fue siempre vista con pesimismo por los habitantes de Costa Rica. Ya desde 1622 hubo peticiones para que el territorio fuera separado del reino de Guatemala y adscrito al reino de Tierra Firme, como se denominaba entonces al istmo, pero nunca surtieron efecto (Fernández, 1970 y Molina, 1991). Por otra parte, los comerciantes de Guatemala, para su propio provecho, adversaban el comercio costarricense con Panamá y en 1811 incluso lograron que se prohibiera, aunque tal medida, que suscitó inmediatas protestas en Costa Rica, fue de breve duración (ibid.).

\section{1.- Costa Rica y Panamá en las Cortes de Cádiz}

Tanto la gobernación de Costa Rica como la intendencia de Panamá estuvieron representadas en las Cortes Constituyentes de Cádiz, la primera por don Florencio del Castillo y la segunda por don José Joaquín Ortiz y Gálvez (Sánchez, 2005). Ambos diputados tuvieron, entre otras preocupaciones comunes, la de la situación en que debían quedar Costa Rica y Panamá en la nueva división política de la monarquía. Al enumerarse las provincias en el artículo 11 de la 
Constitución de $1812^{2}$, ninguna de las dos fue mencionada, por lo que cabía entender que Costa Rica sería parte de la provincia de Guatemala y Panamá de la de Nueva Granada, no obstante los problemas que les representaba la lejanía de las respectivas capitales. El diputado de Costa Rica, en unión con el de Nicaragua, planteó la posibilidad de que además de la provincia de Guatemala, se creara otra en el sur de Centroamérica (Volio, 1980), lo cual se logró el 23 de mayo de 1812, al decidir las Cortes la creación de la provincia de Nicaragua y Costa Rica, con capital en la ciudad de León (Cortes Generales, 1987). El diputado panameño, que formuló, casi al mismo tiempo, la solicitud de que Panamá fuera erigida en provincia, fue menos afortunado, ya que su representada quedó bajo la jurisdicción de Nueva Granada (Sánchez, 2005). En todo caso, el tema perdió interés en 1814, cuando el rey don Fernando VII declaró nula la Constitución y restableció el absolutismo.

\section{2.- Las provincias de 1820}

En marzo de 1820 el rey don Fernando VII tuvo que aceptar el restablecimiento de la Constitución de Cádiz. Esto significó también que se volviera a la organización político-administrativa anterior, en la cual Costa Rica dejaba de ser provincia para convertirse en partido de la provincia de Nicaragua y Costa Rica, en cuya Diputación Provincial de siete miembros había solo dos costarricenses (Sáenz, 1985). La sujeción a las autoridades de León de Nicaragua originó en Costa Rica mucho disgusto, porque aquellas no se preocupaban gran cosa por las necesidades costarricenses y, además, adversaban el comercio de Costa Rica con Panamá (ya en ese mismo año -1820- se planteó la necesidad de recuperar la autonomía y de que se creara una diputación provincial en Costa Rica) (Fernández, 1975). Panamá estaba en igual o peor situación con respecto a las autoridades de Bogotá, ya que además de la distancia entre la ciudad de Panamá y la de Bogotá y la dificultad de los transportes, a Panamá solo le correspondía un representante de los siete que formaban la diputación provincial de Nueva Granada.

\section{3.- Las provincias de 1821}

El 8 de mayo de 1821 las Cortes españolas aprobaron una ley mediante la cual todas las intendencias de la monarquía quedaban erigidas en provincias:

2 Ver Constitución Política de la Monarquía Española de 19 de marzo de 1812, art.11. ${ }^{\circ}$. El texto constitucional figura en CORTES GENERALES, Colección de decretos y órdenes de las Cortes de Cádiz, Madrid, Publicaciones de las Cortes Generales, 1. ${ }^{a}$ ed., 1987, vol. I, pp. 392-451. 
Por ahora en fuerza del artículo 325 de la Constitución, y ampliando el artículo $1^{\circ}{ }^{\circ}$ del decreto de las Cortes generales y extraordinarias de 23 de mayo de 1812 , se establece una diputación provincial en cada una de todas las intendencias de provincia de la España ultramarina en que no esté ya establecida: la residencia de cada una de todas las diputaciones de ultramar es la capital de la intendencia respectiva, y su territorio el que actualmente tiene cada una... ${ }^{3}$

Esta ley representó un duro golpe para las autoridades provinciales de Guatemala, ya que segregaba de su jurisdicción las intendencias de Ciudad Real de Chiapas, Comayagua (Honduras) y San Salvador, convertidas en provincias, cada una de las cuales tendría, en adelante, su propio jefe político superior y su respectiva diputación provincial. En cambio, la ley en nada mejoró la situación de Costa Rica, que no era una intendencia y, en consecuencia, siguió siendo un partido de la provincia de Nicaragua y Costa Rica.

En Panamá la situación era muy particular. Aunque Panamá era una intendencia desde 1807 y la ley le devolvía su autonomía como provincia con respecto a Nueva Granada, el movimiento insurgente o independentista acaudillado por Simón Bolívar ya había logrado expulsar a los españoles de gran parte del territorio neogranadino. El último virrey de Nueva Granada, don Juan de Sámano y Uribarri, había tenido que abandonar Bogotá y se había refugiado a fines de diciembre de 1820 en la ciudad de Panamá, donde murió el 2 de agosto de 1821 (Alba, 1935). Poco después se hizo cargo interinamente del gobierno el general don Juan de la Cruz Murgeón y Achet, quien llegó al istmo en ruta hacia Quito, provincia para cuyo gobierno había sido nombrado, pero que estaba amenazada por los insurgentes (Alba, 1935). Murgeón, liberal y constitucionalista, respetó las libertades consagradas en la Constitución y durante su gobierno se realizaron los comicios para elegir a los integrantes de la Diputación Provincial, de conformidad con la ley de Cortes del 8 de mayo. La jornada final de las elecciones se efectuó el 3 de octubre en la capital panameña (Arosemena, 1999) y poco después se instaló la diputación provincial de Panamá, presidida por el propio Murgeón. Sin embargo, para preparar su expedición a Quito, Murgeón impuso fuertes contribuciones y llevó a cabo una serie de exacciones que en algunos casos fueron verdaderos saqueos, todo lo cual generó fuerte resistencia y hondos rencores contra la autoridad española (Castillero, 1978).

Desde el 26 de julio se había nombrado al brigadier don Tomás Cires, quien se encontraba en Puerto Cabello en Venezuela, como comandante general de Panamá,

3 Decreto $n .^{\circ} 13$ de 8 de mayo de 1821 , art. $1 .^{\circ}$. Su texto figura en Colección de los decretos y órdenes generales expedidos por la Cortes ordinarias de los años de 1820 y 1821 , en el segundo período de su diputación, que comprende desde 25 de febrero hasta 30 de junio del último año. Tomo VII, Madrid, Imprenta Nacional, 1821, pp. 72-73. 
pero la convulsa situación bélica que había allí le impidió ir a tomar posesión del cargo. Por estas circunstancias, cuando el general Murgeón partió hacia Quito el 22 de octubre, dejó encargado del gobierno de la provincia al coronel panameño don José de Fábrega (Alba, 1935), como jefe político superior interino.

\section{4.- La independencia de Nicaragua y Costa Rica}

El 24 de febrero de 1821, el coronel don Agustín de Iturbide proclamó el Plan de Iguala para la independencia de México bajo la forma de un imperio, cuya corona se ofrecería al rey don Fernando VII. El Plan tuvo un éxito inmediato y llevó no solo a la independencia mexicana, sino que enseguida repercutió en Centroamérica. El 15 de septiembre, la Diputación Provincial de Guatemala proclamó la independencia de España y en la misma acta convocó a "las provincias" a elegir diputados a un congreso que debía reunirse en la ciudad de Guatemala. La diputación provincial de Nicaragua y Costa Rica tomó muy a mal las pretensiones hegemónicas guatemaltecas y el 28 de septiembre declaró en León la independencia total y absoluta de Guatemala, así como la independencia provisional de España. Al tener noticia de estos acontecimientos, Costa Rica optó primero por apoyar lo acordado por la diputación provincial, pero enseguida rectificó, temiendo verse envuelta en la rivalidad entre Guatemala y León (Fernández, 1971).

El 11 de octubre de 1821, las autoridades de León proclamaron la independencia absoluta de España y la unión de Nicaragua y Costa Rica al Imperio mexicano. Como consecuencia de esta declaratoria, el 29 de octubre de 1821, en actas distintas, las ciudades de San José y Cartago proclamaron su independencia absoluta de España (Fernández, 1971). No obstante, la élite costarricense era bien consciente de la importancia de que la emancipación no afectara de manera negativa las relaciones mercantiles con Panamá. El 30 de octubre, a solo un día de la firma del acta de independencia, el Ayuntamiento de Cartago tomó el siguiente acuerdo:

Que se pasen oficios al Ayuntamiento de Alanje, Veragua y Panamá, noticiándoles lo ocurrido en esta provincia el día veintinueve del corriente sobre lo plausible que fue a toda esta provincia el citado día por haber prestado en el mismo su juramento absoluto de independencia con el gobierno español, el cual se practicó con la mayor solemnidad y satisfacción general y tranquilidad pública, diciéndoles que este motivo no sirva de obstáculo a nuestra amistad y giros de comercio, que siempre ha ocurrido entre estos habitantes y esos. (Comisión Nacional del Sesquicentenario de la Independencia de Centro América, 1972) 
A propuesta del Ayuntamiento de Cartago, el 12 de noviembre se reunió en esa ciudad una asamblea de representantes de las poblaciones de Costa Rica, que se conoció con el nombre de Junta de Legados de los Pueblos y que el mismo día de su instalación se hizo cargo del gobierno, por haber renunciado el jefe político subalterno español don Juan Manuel de Cañas Trujillo. Después de los titubeos iniciales, los principales actores políticos costarricenses tenían muy claro que no deseaban que Costa Rica continuara sometida a las autoridades de León y tampoco les inspiraban muchas simpatías las de Guatemala, por lo que temporalmente optaron por el autogobierno. La posibilidad de unirse a Panamá, a pesar del antiquísimo anhelo provincial en tal sentido, era en absoluto inviable, dada la subsistencia en el istmo de la autoridad española. De esta forma, uno de los problemas que trató la Junta de Legados fue el de los vínculos marítimos de Costa Rica con Panamá y los peligros que conllevaban en esos momentos. El 20 de noviembre se tomó el siguiente acuerdo:

Habiéndose discutido el riesgo inminente de los buques de esta provincia en la plaza de Panamá intertanto se halle realista, que probablemente serán presa de los realistas; por esto y por otras varias consideraciones que se tuvieron presentes al tiempo de la discusión se acordó negar absolutamente la salida para Panamá a todo buque que lo intente, lo que se publicará por bando en esta ciudad, San José y villas de Heredia y Alajuela.... (Iglesias, 2020)

\section{5.- La independencia de Panamá y la anexión a Colombia}

El 10 de noviembre de 1821, sin tener conocimiento de los recientes sucesos de Costa Rica, pero sí de los éxitos militares de Bolívar, las autoridades de la villa panameña de Los Santos, muy afectada por las exacciones de Murgeón, proclamaron la independencia del Gobierno español, indicando en el acta respectiva que el pueblo estaba "deseoso de vivir bajo el sistema republicano que sigue toda Colombia” (Castillero, 1978: pp. 167-168). Otras poblaciones vecinas imitaron enseguida esta decisión. Alarmadas, las autoridades provinciales de Panamá enviaron comisionados a Los Santos para tratar de que se reconsiderara lo actuado, pero la misión fracasó y esto más bien envalentonó a muchos capitalinos partidarios de la separación de España (ibid.), entre los cuales había un poderoso sector que se sentía perjudicado por las medidas económicas del gobierno peninsular. Por otra parte, se tenía noticia de que, por órdenes de Bolívar, una fuerza militar al mando del general don Mariano Montilla estaba aprestándose en Cartagena de Indias para ir a independizar el istmo del dominio español; si esto ocurría, como era previsible, la élite panameña "quedaría subordinada a la ocupación militar y relegada a un plano subalterno.”(Castillero, 2012). 
Desde tiempo atrás el gobierno del Imperio mexicano había extendido sus miras no solamente sobre el antiguo reino de Guatemala, sino también sobre Panamá, sin duda por comprender su importantísima posición geográfica, $\mathrm{y}$, a la vez, que decidió enviar un ejército para "proteger" a Guatemala, es decir, asegurarse de la anexión de Centroamérica al Imperio, incluyó entre los objetivos de esa expedición a Panamá, según lo indicó el 8 de octubre el generalísimo Iturbide, presidente de la Regencia de México, en una carta a don Manuel Flon y SaintMaixench, conde de la Cadena, designado como jefe de la fuerza protectora (Valle, 1936). De manera adicional, se enviaron unos comisionados a la capital istmeña, con el fin de promover la causa imperial (Castillero, 1978). Cabe recordar que teóricamente el soberano de México iba a ser el propio rey don Fernando VII o un príncipe de su familia, por lo que el plan podía, de forma eventual, contar con simpatías entre las propias autoridades españolas de Panamá, como ocurrió en varias provincias centroamericanas.

El 28 de noviembre, en un ambiente de gran tensión creado por las declaratorias independentistas de Los Santos y otras poblaciones, se amotinó el pueblo de la ciudad de Panamá a favor del sistema republicano y pidió la reunión de un cabildo abierto. El Ayuntamiento accedió a celebrarlo e invitó a hacerse presentes al jefe político Fábrega, los miembros de la diputación provincial, el obispo diocesano monseñor José Higinio Durán Alcocer y otras autoridades. Hubo una agitada reunión, en la cual se discutió, como primer punto, el tema de la separación de España, que fue aprobada sin mayores objeciones (Castillero, 1978).

Mucho más acalorada fue la discusión acerca de ¿cuál debía ser el camino a seguir? Un grupo dirigido por el obispo Durán Alcocer, que era peruano, planteó la posibilidad de la unión al Perú, cuya independencia había sido proclamada en Lima por el general don José de San Martín, el 28 de julio de 1821 y los comisionados de México gestionaban a favor del imperio. Pero el criterio que prevaleció fue el de la unión a la República de Colombia, cuya Constitución había sido aprobada en Cúcuta el 30 de agosto y, en consecuencia, el acta de la reunión consagró en su artículo 2..$^{\circ}$ que: "El territorio de las provincias del Istmo pertenece al Estado republicano de Colombia, a cuyo Congreso irá a representarlo oportunamente su diputado” (Castillero, 1978: pp. 178-179).

Sin embargo, parece claro que se esperaba algún tipo de federalismo (Arosemena, 1982), ya que el artículo 9. indicó que "El Istmo, por medio de sus Representantes, formará los reglamentos económicos convenientes para su gobierno interior." (Castillero, 1978: pp. 178-179) El acta fue firmada por Fábrega, quien se mantuvo al frente del Gobierno como jefe político superior, el obispo, los diputados provinciales y demás autoridades presentes y, de este modo, quedó decidida la independencia de España y la unión a Colombia. 
Podría parecer paradójico que Panamá, después de haber logrado hacía muy poco la anhelada autonomía con respecto al gobierno provincial de Bogotá, resolviera tan rápido su anexión a Colombia. Ciertamente, Bolívar, que había derrotado a los españoles en Nueva Granada con asombrosas acciones militares, era visto con una enorme admiración y podía creerse sinceramente en que la naciente República colombiana iba a ser un éxito. Pero había otros motivos de más peso. Para empezar, no había muchas otras opciones viables. El mantenimiento de la fidelidad a España no ofrecía ninguna ventaja tangible y posiblemente hubiera expuesto al istmo a la amenaza de una intervención militar colombiana o mexicana, y los centros de poder de México y Perú eran aún más distantes de Panamá que Bogotá. Por otra parte, el historiador panameño Moisés Marín Chong indica que, aunque fue un aspecto olvidado por la historiografía tradicional, en el anexionismo de ese momento tuvo gran importancia el factor económico:

Si la cesación de las concesiones mercantiles hechas al Istmo por la Corona española, contribuyeron a crear una mentalidad independentista, esta brusca separación trajo como consecuencia una virtual paralización en las actividades comerciales e industriales y el país se veía ante una situación precaria. En tal situación el anexionismo pareció a los próceres del Istmo como la única salida para detener el descenso económico al cual se abocaba el país. Según este criterio, el Istmo iba a gozar de estabilidad si se cobijaba bajo la protección de una nación poderosa; los comerciantes de las ciudades terminales y los propietarios del agro, viendo en peligro sus fortunas por esta brusca interrupción mercantil, hicieron todo lo posible, a juicio de este autor, para unirse a Colombia, a riesgo de su recién adquirida autonomía. (Chong, 1998: p. 112)

Al igual que había ocurrido en Costa Rica en octubre de 1821, en ese momento nadie pensó seriamente en que Panamá pudiera subsistir como un estado independiente, o por lo menos no se planteó tal posibilidad. Al día siguiente de la proclamación, el coronel Fábrega dirigió una comunicación a Simón Bolívar, presidente de Colombia, para enterarlo de lo decidido e implorar la protección de su gobierno (O’Leary, 1883). Esta nota fue respondida por el general Francisco de Paula Santander, encargado del poder por ausencia de Bolívar, con otra fechada en Bogotá, el 17 de enero, en la cual le decía:

Yo me complazco en declarar a los pueblos del Istmo, que el Gobierno de Colombia los acoge con transportes de júbilo, que los mirará, sin distinción de los demás pueblos libres de la República, y que los gobernará por las leyes, por las cuales gobierna a los departamentos antiguos. (O' Leary, 1883: p. 134) 
El mismo documento anunciaba el envío de una fuerza militar para la protección del istmo. Pero a pesar del tono cordial de la carta, reiterado también en otra que el 1. ${ }^{\circ}$ de febrero envió Bolívar a Fábrega (Castillero, 1978), desde el principio quedó claro que no habría para Panamá ningún estatus especial. El 9 de febrero, Santander decretó el establecimiento de un Departamento de las provincias del istmo y nombró al coronel venezolano, don José María Carreño, como intendente y comandante general. A Fábrega se le dio el cargo de gobernador de Veraguas, que había solicitado (Castillero, 1978). Como consecuencia de estas disposiciones, e ignorando lo establecido en el artículo 9. del Acta del 28 de noviembre, también habría de disolverse la diputación provincial de Panamá. Más tarde, el Congreso de Colombia rehusó la aprobación expresa de esa Acta, por cuanto suponía el reconocimiento, por la República, de la deuda interna panameña como nacional (Castillero, 1978). Mal empezaba la vida del istmo como parte de Colombia y las cosas no tardarían en empeorar:

Las consecuencias del anexionismo se harían sentir luego cuando los intereses centralistas de Bogotá echaron por el suelo el principio que se suponía ínsito en nuestros deseos de encontrar protección bajo Colombia, cuando cundió la malquerencia y el trato injusto contra los distintos sectores que componían el país panameño. (Chong, 1998: p. 112)

\section{6.- Anexión de Costa Rica al Imperio mexicano y el comercio con Panamá}

El 1. ${ }^{\circ}$ de diciembre de 1821 la Junta de Legados de los Pueblos, erigida en asamblea constituyente, aprobó en forma provisional el Pacto Social Fundamental Interino o Pacto de Concordia, primer texto constitucional costarricense después de la separación de España y para cuya vigencia definitiva se requeriría la ratificación de otra constituyente, formada por electores designados por los pueblos.

En los días finales de 1821 o a principios de enero de 1822 se tuvo conocimiento en la capital costarricense, sin duda con gran alivio, de la independencia de Panamá. El acta de la sesión celebrada por el Ayuntamiento de Cartago el 3 de enero de 1822 consignó:

Que aunque no han sido oficiales las noticias de Tierra Firme, con todo, siendo de particulares fidedignos que anuncian haberse jurado la independencia el 28 de noviembre en la ciudad de Panamá y sucesivamente en lo restante de aquel Istmo, se comunique a los tres ayuntamientos de León, Granada y Nicaragua [Rivas] (...) Que para averiguar la realidad de varias 
noticias que se han difundido en esta, sobre la salida del ejército europeo para Guayaquil y otros incidentes de esta especie, se reciba declaración en forma del sargento Francisco Roldán, que acaba de llegar de dicho Panamá y es sujeto fidedigno para dar el ascenso a su relato. (Comisión Nacional del Sesquicentenario de la Independencia de Centro América, 1972: p. 168)

El 6 de enero se reunió en Cartago la Junta de Electores, que el 10 del mismo mes acordó dar vigencia definitiva al Pacto de Concordia con varias reformas, la más importante de las cuales era que Costa Rica se anexaba de manera condicional al Imperio mexicano. Sin embargo, los constituyentes tomaron en cuenta la importancia de los vínculos comerciales con Panamá, que sin duda se habían visto gravemente afectados por la interrupción de las comunicaciones marítimas dispuesta por la Junta de Legados y que, de forma eventual, podían ser severamente obstaculizados por el Gobierno mexicano, como lo habían hecho las autoridades de Guatemala y León. Al aprobar las reformas al Pacto, los constituyentes dispusieron que la Junta Superior Gubernativa que iba a asumir el Gobierno de Costa Rica debía enviar a la Regencia de México el Pacto adicionado

... haciendo manifestación de las circunstancias particulares en que se halla la provincia respecto al Istmo de Panamá por su vecindad y relaciones, y la necesidad que tiene de que se perpetúe el comercio que ha tenido por mar y tierra, sin el cual no podrá subsistir. (Iglesias, 2020: p. 78)

\section{7.- Las primeras comunicaciones entre la Junta Gubernativa de Costa Rica y las autoridades de Panamá}

El 13 de enero de 1822 tomó posesión, en Cartago, la Junta Superior Gubernativa, primer gobierno constitucional costarricense elegido popularmente. El 31 de enero, con base en una norma del Pacto de Concordia, la Junta acordó permitir el ingreso de Costa Rica a todo tipo de bienes de consumo, procedentes de puertos americanos o de naciones amigas (Iglesias, 2020). Esta disposición posiblemente se tomó teniendo en mente la relevancia del comercio con Panamá, de donde provenían las principales mercaderías importadas. Pero es muy probable, además, que, en estos días iniciales de su gestión, la Junta se haya dirigido al Ayuntamiento de la ciudad de Panamá para tratar de obtener una confirmación oficial de la Independencia istmeña y saber cuál era su actitud. Aunque las lacónicas actas de Junta nada dicen al respecto, se deduce la existencia de tal comunicación por el hecho de que en la del 25 de febrero, al hablar de la recepción del Acta de Independencia panameña, se dijo: "Habiéndose recibido contestación del Excelentísimo Ayuntamiento de la libre Panamá...” (Iglesias, 
2020: p.107) (el subrayado es nuestro). Cabe recordar, además, que el artículo 45 del Pacto de Concordia indicaba que la Junta entablaría "comunicaciones y correspondencia fraternal con los gobiernos de las otras provincias, concertando las relaciones de interés público y recíproco" (Iglesias, 2020: p. 52).

Por su parte, al asumir el Gobierno de Panamá, el intendente don José María Carreño dirigió una comunicación a la Junta Gubernativa costarricense. Lamentablemente este texto no se conserva, pero por otro documento se sabe que en él se hacía referencia a la identidad de principios que animaba a ambos pueblos y la necesidad de estrechar todas sus relaciones ${ }^{4}$. Además, la Junta recibió un ejemplar del reglamento emitido en Panamá, el 31 de diciembre de 1821, con respecto a los impuestos que debían pagar las importaciones ${ }^{5}$. Por su parte, el Ayuntamiento de la ciudad de Panamá le remitió el Acta de Independencia del Gobierno español firmada allí el 28 de noviembre de 1821 (Iglesias, 2020).

Mientras se deterioraban progresivamente las relaciones entre autoridades de Cartago y las de León, la Junta costarricense estaba procurando entablar buenas relaciones con otras autoridades de la región. El 18 de febrero de 1822 dispuso felicitar a la Junta Gubernativa recién constituida en Granada de Nicaragua (Iglesias, 2020) y enviar a esa ciudad un comisionado, y el 19 dirigió una nota de congratulaciones por su instalación a la Junta Gubernativa formada en San Salvador ${ }^{6}$. En esa coyuntura, los documentos panameños fueron sin duda recibidos con complacencia. El 25 de febrero, la Junta acordó que se felicitara, de forma afectuosa, al Ayuntamiento de Panamá y se le comunicara "la actitud política y de fraternidad de esta provincia respecto de aquella." (Iglesias, 2020: pp.107-108). Sin embargo, la cuestión de los impuestos a las importaciones preocupó a la Junta, que además de hacer circular en Costa Rica el reglamento panameño sobre la materia (Iglesias, 2020), el mismo 25 de febrero acordó manifestar al de Panamá la esperanza de que se exonerara de derechos, en lo posible, a los productos agrícolas costarricenses:

... que al Gobierno de Panamá se le conteste con la debida gratitud con concepto a que disfrutará esta provincia en sus relaciones comerciales, las consideraciones que se conceden por los artículos $1^{\circ}$ y 12 en las disposiciones generales de dicho reglamento y de la íntima fraternidad a que la naturaleza estrecha ambas provincias por su posición e identidad de intereses y mutuas necesidades; pero que bajo este concepto, y de que los frutos de esta provincia a que se contraes u comercio con aquella, son necesarios a su consumo y a esta de poca utilidad en razón de que su valor intrínseco

4 Ver Archivo Nacional de Costa Rica, Sección Histórica, Provincial Independiente, n. ${ }^{\circ} 189$.

5 Ver Archivo Nacional de Costa Rica, Sección Histórica, Provincial Independiente, n. ${ }^{\circ} 310$.

6 Ver Archivo Nacional de Costa Rica, Sección Histórica, Provincial Independiente, n. ${ }^{\circ} 349$ y n. ${ }^{\circ} 350$. 
es muy despreciable con respecto a los gastos de transporte por su crecido volumen, se espera que aquel Gobierno por conveniencia recíproca se sirva indultar los frutos indicados de los derechos de entrada cuanto sea dado a su autoridad. (Iglesias, 2020: p. 107)

Adicionalmente, y dado que se esperaba contar en Costa Rica con importantes excedentes de tabaco, se le ofreció a Panamá ese producto, bajo los mismos principios y condiciones que se habían observado con anterioridad ${ }^{7}$.

Las respuestas que meses después se recibieron de Carreño no fueron muy propicias para el entusiasmo. Si bien, en una nota del 16 de abril ofrecía protección y hospitalidad a todos los pueblos de Centroamérica por parte de la República de Colombia en otra, del 20 de abril, aunque agradecía el ofrecimiento del tabaco costarricense y pedía los precios del producto puesto en los muelles panameños, también le manifestaba que gracias a un "comercio generoso", en Panamá abundaba el tabaco de Cuba y de Virginia.

En la sesión del 19 de abril la Junta conoció y aprobó el texto de una exposición dirigida a la Regencia del Imperio mexicano, en la cual, de conformidad con las reformas al Pacto de Concordia, se le indicaba la importancia de los vínculos comerciales entre Costa Rica y Panamá:

... así como la naturaleza ha estrechado y unido a esta provincia en su posición geográfica con el Istmo de Panamá, la ha hecho igualmente partícipe de las ventajas para el comercio de aquel punto, que es el único canal por donde circulan los artículos de su industria agrícola, base sola de su subsistencia, y por el cual reporta con comodidad los que para su consumo necesita de las otras regiones; y siendo por consiguiente de la mayor necesidad y conveniencia a la provincia estas relaciones, ellas han producido igualmente las de amistad y armonía de sentimientos, por lo que no podría la provincia separase de ellas, sino es sacrificando del todo su propia existencia. (Iglesias, 2020: pp.127-128)

Antes de enviar este documento a México, la Junta lo circuló a los ayuntamientos. El de la villa de Alajuela lo interpretó en el sentido de que la Junta Gubernativa pretendía separar a Costa Rica del Imperio y unirla a Colombia por medio de Panamá, lo cual motivó, el 18 de abril, una exaltada reacción adversa en los munícipes alajuelenses, que calificaron tal idea de errada, nociva e inasequible ${ }^{8}$. La Junta tuvo que enviar a dos de sus vocales a Alajuela, para explicar que no se

7 Ver Archivo Nacional de Costa Rica, Sección Histórica, Provincial Independiente, n. ${ }^{\circ} 189$.

8 Ver Archivo Nacional de Costa Rica, Sección Histórica, Municipal, n. ${ }^{\circ} 66$. 
tenía en mente semejante cosa, lo cual hizo que el Ayuntamiento se retractara el 6 de mayo de sus manifestaciones ${ }^{9}$.

Fuera de algunas notas sobre el sistema de $\operatorname{correos}^{10}$, durante el resto de 1822 no volvió a haber comunicaciones entre los gobiernos de Costa Rica y el istmo.

\section{8.- La anexión de Costa Rica a Colombia}

En febrero y marzo de 1823 hubo vigorosos movimientos en Costa Rica a favor de la unión a Colombia, cuyo principal promotor fue el bachiller Rafael Francisco Osejo, una de las principales figuras republicanas del momento (Fernández, $1971)^{11}$. La agitación política llevó a que se reuniera en Cartago un congreso provincial, hecho que la Junta Gubernativa puso en conocimiento del gobierno de Panamán ${ }^{2}$.

El 12 de marzo, el Congreso Provincial Constituyente reunido en Cartago aprobó, por 19 votos contra 5, que Costa Rica se constituía en república federada con Colombia y dispuso enviar un correo extraordinario a Bolívar para enterarlo "de tan grandioso acontecimiento" (Iglesias, 2020: pp. 350-351); pero en la misma sesión se decidió revocar esas determinaciones. El 14 de marzo volvió a examinarse el tema y otra vez, por 19 votos contra 5, se acordó ya no constituir a Costa Rica en república federada con Colombia, sino ponerla bajo su protección y garantía (Iglesias, 2020; p. 353). Muy poco duró este rumbo, porque en el Estatuto Político que se aprobó el 19 de marzo, en reemplazo del Pacto de Concordia, se dijo que Costa Rica era libre e independiente y que el Congreso decidiría de qué potencia sería dependiente, sin hacer ninguna referencia a Colombia (Sáenz, 1985).

La Diputación de Costa Rica, órgano colegiado que por decisión del Congreso reemplazó a la Junta Gubernativa el 20 de marzo, envió el 21 de ese mes una comunicación al intendente Carreño para enterarlo de su ascenso al poder,

9 Ver Archivo Nacional de Costa Rica, Sección Histórica, Municipal, n. ${ }^{\circ} 332$.

10 Ver Archivo Nacional de Costa Rica, Sección Histórica, Gobernación, n. ${ }^{\circ} 23850$; Hacienda, n. ${ }^{\circ} 8551$; Provincial Independiente, $n .{ }^{\circ} 607$.

11 Cabe indicar que Osejo, titulándose falsamente comandante, escribió el 3 de febrero al intendente Carreño y a Bolívar, es posible que en procura de obtener apoyo para la causa republicana. No se conoce el texto de esas cartas, aunque sí se sabe de su existencia gracias al aviso de recibido que dio Carreño en septiembre de ese año, mediante un oficio dirigido "al comandante Rafael Francisco Osejo". Para estos efectos ver: Archivo Nacional de Costa Rica, Sección Histórica, Provincial Independiente, $n .^{\circ}$ 687. En febrero de 1823 Osejo no era comandante ni tenía ningún cargo en el Gobierno de Costa Rica.

12 Ver Archivo Nacional de Costa Rica, Sección Histórica, Provincial Independiente, n. ${ }^{\circ} 828$. 
pero no hizo referencia a la posible anexión a Colombia. La nota no fue contestada por Carreño sino hasta el 6 de junio ${ }^{13}$, cuando ya la Diputación había dejado de existir.

Todas estas oscilaciones se debían, en concreto, al temor de una intervención militar en Costa Rica de las autoridades imperiales ubicadas en León de Nicaragua, las cuales ya estaban atacando la ciudad de Granada, también hostil a la hegemonía leonesa. Sin embargo, en cuanto los monárquicos costarricenses fueron derrotados por los republicanos en la batalla de Ochomogo y se disipó la amenaza militar del Imperio por la caída de este en México y la deposición en León de las autoridades imperiales, no se volvió a hablar en Costa Rica de una anexión a Colombia o de un posible protectorado colombiano. En octubre de 1823, cuando el Congreso Provincial tuvo que decidir definitivamente sobre el tema de a qué país se anexaría Costa Rica, se optó por la adhesión a las Provincias Unidas del Centro de América, es decir, a la naciente federación centroamericana.

¿Por qué no se pensó en la unión a Colombia? Nada dicen al respecto las sucintas actas del Congreso Provincial, pero es de suponer que gracias al comercio entre Costa Rica y el istmo, los círculos dirigentes costarricenses estaban bien enterados de que la situación de Panamá, en aquellos momentos, no era nada halagüeña. Además del rígido sistema centralista impuesto al istmo por las autoridades colombianas, había otros graves problemas que no eran para estimular en lo más mínimo el anexionismo costarricense. Debido a que en Sudamérica continuaba la guerra contra los últimos vestigios de la autoridad española, Panamá se había visto muy afectada:

... tratándose de un puerto de tamaña importancia militar, cual era el Istmo para la campaña del Sur, sus puertos entrambos lados se vieron extraordinariamente concurridos y su tesoro agotado hasta el punto que fueron necesarios nuevos impuestos, casi en su totalidad doblados ya por aquel entonces, y recurrir a otros expedientes extraordinarios para acopiar fondos. (Alba, 1935: p. 89)

Participar en la naciente república centroamericana podía no ofrecer grandes esperanzas a Costa Rica, pero esta, al menos, podría enviar diputados a la Asamblea Constituyente que estaba reunida en Guatemala para que participaran en la definición de la forma en que se organizaría esa república y, además, era casi seguro que lo haría de modo federal. Por el contrario, anexarse a Colombia hubiera significado incorporarse, de modo incondicional, a un sistema

13 Ver Archivo Nacional de Costa Rica, Sección Histórica, Provincial Independiente, n. ${ }^{\circ} 464$. 
centralista ya en funcionamiento, que a Panamá no le había dado ningún trato especial y que menos se lo iba a dar a Costa Rica, bastante menos importante que el istmo en lo estratégico y en lo económico.

\section{Conclusiones}

Es posible que de no haber existido la amenazante triangulación España-México-Colombia, en 1821 Costa Rica y Panamá hubieran podido negociar la posibilidad de constituir juntas un nuevo Estado soberano independiente de esas tres potencias. Desde años atrás existían simpatías y contactos frecuentes entre costarricenses y panameños y la economía agropecuaria de Costa Rica y la comercial del istmo se complementaban de un modo mutuamente ventajoso.

Ni en Costa Rica ni en Panamá existía una fuerte tradición autoritaria y jerárquica, lo cual hubiera sido una ventaja común para el desarrollo de un sistema democrático y una especie de confederación entre iguales. En aquellos azarosos tiempos no surgió, sin embargo, ninguna coyuntura favorable para una negociación de ese tipo. De modo prematuro y por la fuerza de las circunstancias, Panamá se unió a Colombia y Costa Rica a México, si bien, en el caso costarricense, la anexión se hizo con menos premura y de un modo condicional, que a la larga le posibilitó consolidar un sistema de autogobierno que al istmo no se le permitió. Podría decirse que, entre depender de España, Guatemala, León y México, Costa Rica escogió al imperio como el mal menor, y con la esperanza de tener sus autoridades propias. Panamá solo pudo escoger entre España y Colombia.

En 1903, cuando Panamá logró por fin su independencia política definitiva, las circunstancias por supuesto eran muy distintas. Costa Rica tenía ya su propio rumbo y Panamá empezó el suyo. Sin embargo, como dato curioso y para cerrar este breve estudio, cabe recordar que en la prensa costarricense de 1903 hubo alguna voz aislada a favor de ese antiguo anhelo unionista que nunca se materializó. El 7 de noviembre, a los pocos días de la separación de Panamá de Colombia, el periódico josefino El Derecho, que dirigía don Rogelio Fernández Güell, años después mártir de las libertades patrias, publicó un emotivo editorial, posiblemente salido de la pluma de ese gran hombre público, que se titulaba "Ha llegado la hora" y que expresaba:

Es un hecho, pues, que Panamá se ha independizado de Colombia.

La naturaleza prepara grandes acontecimientos en busca del equilibrio físico y social. Costa Rica y Panamá están llamadas a formar una sola nación. La lógica así lo indica regida por el común interés de ambos pueblos. El 
territorio panameño no es sino una prolongación del Centro Americano: la América del Sur comienza allí donde concluye el Istmo.

La oportunidad se ha presentado y debemos aprovecharla: de lo contrario probaríamos que tenemos cerrados los ojos a la civilización y la espalda vuelta al porvenir. Trabajemos, sí, por la unión de estos dos países cuya ventajosa posición en el Globo, les destina -como decía Bolívar- a ser asiento de la capital del mundo.

En cuanto al punto en donde deba establecerse el centro del Gobierno, ya se escogerá el que más convenga a los dos pueblos: nada de egoísmos y pensemos alto.

El verdadero patriotismo nos lleva a perseguir la unión con Panamá, pues vemos en ella la felicidad y el engrandecimiento de nuestra patria.

Panameños, aquí están vuestros hermanos! Costarricenses, saludad a vuestros compatriotas de mañana, y jadelante! $!^{14}$

\section{Referencias}

Alba C., M. (1935). "Cronología de los Gobernantes de Panamá 1510-1932", en Boletín de la Academia Panameña de la Historia, Panamá, N. ${ }^{\circ}$ 8, enero, abril y julio, pp. 3-182.

Archivo Nacional de Costa Rica, Sección Histórica. Gobernación, n. 23850.

Archivo Nacional de Costa Rica, Sección Histórica. Hacienda, n. ${ }^{\circ} 8551$.

Archivo Nacional de Costa Rica, Sección Histórica. Municipal, n. ${ }^{\circ} 66$ y n. 332.

Archivo Nacional de Costa Rica, Sección Histórica. Provincial Independiente, n. ${ }^{\circ}$ 189 , n. 310 , n. 349 , n. ${ }^{\circ} 350$, n. 464 , n. 607 , n. 687 y n. 828 .

Arosemena, J. (1982). El estado federal de Panamá, Panamá, Editorial Universitaria, $1 .^{\mathrm{a}}$ ed.

Arosemena, M. (1999). Apuntamientos históricos, Panamá, Autoridad del Canal de Panamá, $1 .^{\mathrm{a}}$ ed.

Castillero C., A. (2012). "La Constitución Gaditana de 1812 y su influencia en Panamá: 1808-1821, en Memorias: Revista Digital de Historia y Arqueología

14 Fragmento disponible en: "Ha llegado la ahora", en El Derecho, San José, 7 de noviembre de 1903, n. ${ }^{\circ} 605$, p. 2. 
desde el Caribe, Barranquilla, n. ${ }^{\circ}$ 18, setiembre-diciembre. http://www.scielo.org.co/scielo.php?script=sci_arttext\&pid=S1794-88862012000300004

Castillero, Ernesto J. (1978). Raíces de la independencia de Panamá, Panamá, Academia Panameña de la Historia, $1 .^{\text {a }}$ ed.

Chong M., M. (1998). Historia de Panamá, Panamá: Editorial Chong Ramar, 1. ${ }^{\mathrm{a}}$ ed. (1821). Colección de los decretos y órdenes generales expedidos por la Cortes ordinarias de los años de 1820 y 1821, en el segundo período de su diputación, que comprende desde 25 de febrero hasta 30 de junio del último año. Tomo VII, Madrid, Imprenta Nacional, 1821.

Comisión Nacional del Sesquicentenario de la Independencia de Centro América. (1972). Actas y correspondencia del Ayuntamiento de Cartago (1820-1823), San José, Imprenta Nacional, 1. ${ }^{\mathrm{a}}$ ed.

Cortes Generales. (1987). Colección de decretos y órdenes de las Cortes de Cádiz, Madrid, Publicaciones de las Cortes Generales, 1. ${ }^{\text {a }}$ ed., 2 vols. . (7 de noviembre, 1903). El Derecho, San José, n. ${ }^{\circ} 605$.

Fernández, L. (1975). Historia de Costa Rica durante la dominación española 1502-1821, San José, Editorial Costa Rica, 1. ${ }^{a}$ ed., 1975.

Fernández G., R. (1970). Cartilla histórica de Costa Rica, San José, Antonio Lehmann, 44. ${ }^{\mathrm{a}}$ ed.

Fernández G., R. (1971). La Independencia, San José, Comisión Nacional del Sesquicentenario de la Independencia de Centroamérica, $1{ }^{a}$ ed.

Fonseca C., Elizabeth, y et al. (2001). Costa Rica en el siglo XVIII, San José, Editorial de la Universidad de Costa Rica, 1. ed.

Iglesias, F. (2020). Documentos relativos a la Independencia, San José, EUNED, 3 vols.

Molina J., I. (1991). Costa Rica (1800-1850). El legado colonial y la génesis del capitalismo, San José, Editorial de la Universidad de Costa Rica, 1. ${ }^{a}$ ed.

O'Leary, D. (1883). Memorias del general O'Leary Tomo XIX. Documentos, Caracas, Imprenta de "El Monitor", 1. a ed.

Sáenz C., J. (1985). El despertar constitucional de Costa Rica, San José, Asociación Libro Libre, $1 .^{\mathrm{a}}$ ed.

Sánchez G., S. (2005). "Los primeros diputados panameños: Ortiz y Carbacas en las Cortes Españolas", en Foro Constitucional Iberoamericano, Madrid, n. ${ }^{\circ}$ 11, pp. 92-135. 
Solórzano F., J. (1984). “Costa Rica colonial: una síntesis interpretativa”, en Costa Rica colonial: tres ensayos, San José, Programa Interamericano de Ciencias Sociales, $1 .^{\text {a }}$ ed., pp. 15-43.

Valle, R. (1936). La anexión de Centro América a México (Documentos y escritos de 1821-1822). Tomo III, México, Publicaciones de la Secretaría de Relaciones Exteriores, 1. ${ }^{\mathrm{a}}$ ed.

Volio B., M. (1980). Costa Rica en las Cortes de Cádiz, San José, Editorial Juricentro, $1 .^{\mathrm{a}}$ ed. 